groups in each apparatus had an inescapable shock of fixed duration of $0.5,1,2$, or $4 \mathrm{sec}$. The fifth group had the normal escape contingency, and the sixth group had inescapable shock of varied duration, the duration on any one trial being the mean of the duration effected by $S$ s with the escape contingency. In effect, these last Ss, the matched group, were yoked to the escape group. In the one-way apparatus, running time, and hence shock duration, fell in a few trials to a minimal value close to $1.5 \mathrm{sec}$. In the wheel, running times were very close to $1.0 \mathrm{sec}$, even at the beginning of training. When it became apparent that the yoked group would duplicate the $1-\sec$ group, it was abandoned, and the $1-\mathrm{sec}$ group taken to be an appropriate substitute.

\section{RESULTS AND DISCUSSION}

The median number of $R_{a}$ s for each group over the course of training is given in Fig. 1 . It is obvious that shock duration on nonavoidance trials has no effect upon overall avoidance performance except in the case of the shortest shocks used, i.e., $0.5 \mathrm{sec}$. At this minimal value of shock there was a serious loss in both kinds of apparatus, perhaps because such short shocks fail to produce an adequate level of motivation. It could be argued that performance in most cases was so good that there was little room for any improvement attributable to the possibility of escaping shock on nonavoidance trials. That is, the high overall level of performance might mask a small but real contribution of the escape contingency to avoidance learning. One way to answer this question is to examine the relative performance early in training before performance has approached its ceiling. Such data for the first 10-trial block are shown in Fig. 2. The results from the first trials are naturally more variable than the overall scores, but the same general pattern is apparent: There is some loss of performance, or failure to learn with the shortest checks, but over most of the range of duration of inescapable shock, performance is indistinguishable from the performance of Ss that escape shock. The conclusion must be that, in these two avoidance learning situations, the escape contingency makes no apparent contribution to the acquisition of $R_{a}$. The reason this is so, we would suggest, is that the response that is required of $S$ in both of these situations is an effective species-specific defense reaction. In both the wheel and the one-way apparatus, running permits the rat to get away, in some sense at least, and running is acquired as an $R_{a}$ in these situations purely and simply because running does permit $S$ to get away. According to this account (Bolles, in press) it is immaterial that the situation is arranged so that running actually avoids shock, and as we have found here, it is also immaterial whether the situation is arranged so that the same running response can also escape shock. Under these conditions $R_{a}$ is rapidly acquired apparently without benefit of what is ordinarily considered to be one of the important reinforcement contingencies.

\section{REFERENCES}

BOLLES, R. C. Avoidance and escape learning: Simultaneous acquisition of different responses. Journal of Comparative \& Physiological Psychology, in press.

BOLLES, R. C., STOKES, L. W., \& YOUNGER, M. S. Does CS termination reinforce avoid ance behavior? Journal of Comparative \& Physiological Psychology, 1966, 62, 201-207.

\section{NOTE}

1. Supported by National Science Foundation Grant GB-8035.

\title{
Motivation and learning in a water maze
}

\section{CONSALVI, American University of Beirut, Beirut, Lebanon}

Studies of the learning behavior of rats in a water maze are presented. A total of 135 Ss, in 12 groups, were subjected to water temperatures from 60 to $110 \mathrm{deg} F$. Performance was assessed in terms of percentage of leamers, trials, errors, and time for each temperature. The results suggest that learning is a nonmonotonic function of temperature with peak performances in the regions of 80 and $110 \mathrm{deg}$. while motivation increases unidirectionally as water temperature diverges from that of the body.

This is a report of three separate studies of the leaming behavior of rats in a water maze that was designed and constructed by the writer. The project was initiated in order to provide a task for drug studies in which the difficulty level could be varied, massed trials applied, and motivation manipulated without recourse to deprivation schedules or shock.

A number of studies have appeared in which the behavior of rats or mice has been examined in a task involving swimming. The apparatus employed has consisted of swimways, fixed $T$-mazes, or water versions of the Lashley III; in general, these tasks have not permitted variation in difficulty level. Of interest here are several studies of learning and motivation as a function of water temperature. (All temperatures will be cited in Fahrenheit units throughout this paper.)

Wever (1932) studied the effects of eight water temperatures between 50 and $113 \mathrm{deg}$ on the time scores of rats in a swimway and found that trial time increased as temperature increased from 50 to $104 \mathrm{deg}$ and decreased at $113 \mathrm{deg}$.

Hack (1933) exposed rats to three temperatures in a simple water maze, 59 , 99.5 , and $113 \mathrm{deg}$. The lowest temperature showed the fastest drop in time scores and the highest produced about the same time scores though with a few more trials. The 99.5-deg group maintained much higher scores than either of the other two groups.

Waller et al (1960) used three groups of mice in a simple maze at three water temperatures, $68,80.6$, and $93.2 \mathrm{deg}$. They found that time scores differed significantly as a function of temperature on the 1 st day and continued to do so on the 12th day. Time increased with temperature for all groups. Over 12 days of testing, the groups at 68 and $80.6 \mathrm{deg}$ showed a decre ase in time scores, whereas the group at $93.2 \mathrm{deg}$ showed an increase. Error scores did not differ across groups as a function of temperature.

\section{APPARATUS}

The water maze consisted of a galvanized sheet-metal tank 96 in. long, 12 in. wide, 18 in. deep, which was separated into six compartments by five pairs of guillotine gates. A start box opened directly into the first compartment, and a ramp at the other end of the tank led to a heated platform. In each of the first five compartments, a sheet-metal baffle was mounted vertically between the two adjacent gates; this extended 4.5 in. into the compartment creating definite approaches (or blinds) to each of the gates. Above $70 \mathrm{deg}$, the water flowed through the tank continuously with the temperature controlled by a mixing valve. Temperatures below $70 \mathrm{deg}$ were established with ice and a continuous flow was not possible. (The maze contained $8 \mathrm{cu} \mathrm{ft}$ of water and heat transfer was slow.) PROCEDURE

At the start of each trial, $\mathrm{S}$ was lowered into the water, and the trial time recorder was started. $S$ was permitted to swim in each compartment until his body, exclusive of the tail, was situated in the approach to the correct gate; $\mathrm{E}$ raised the gate and $\mathrm{S}$ swam into the next compartment. If $S$ failed to 
make the correct response within the set time limit, he was guided through the correct gate and this was noted. (Some animals in the early trials, or at certain temperatures, adopted the practice of "holding," i.e., they would grasp the baffle between the gates and not swim around in the compartment. Rats which persisted in the practice beyond the 10th trial were discontinued and classified as nonlearners. It had been found that $S$ s which did this for as long as 10 trials were highly likely to continue doing so beyond 30 trials.) The procedure was the same for each compartment. Trial time stopped when $\mathrm{S}$ passed through the last gate. The amount of rest following each trial was assigned on the basis of the duration of the trial.

The scores recorded were trials to criterion, time/trial, errors/trial, and per cent leamers in each group. Medians were used as estimates of central tendency for groups. The scoring of errors was based on the division of each compartment into four quadrants, one correct and three incorrect. Two of the quadrants were the approaches to the gates, enclosed on three sides; the other quadrants were demarcated by visually extending the baffle between the gates. An error was scored each time $S$ entered an incorrect quadrant. Trials were continued until S met one of three criteria: two consecutive errorless trials; exceeding 20 trials for Study A or 30 for B and C; exceeding the time limit for two compartments in each of two consecutive trials beyond the 10th.

\section{SUBJECTS}

The rats were experimentally naive males of the Long-Evans hooded variety. They were about 105 days old and averaged $350 \mathrm{~g}$ at the time of testing. The Ns and temperatures for the groups in each study

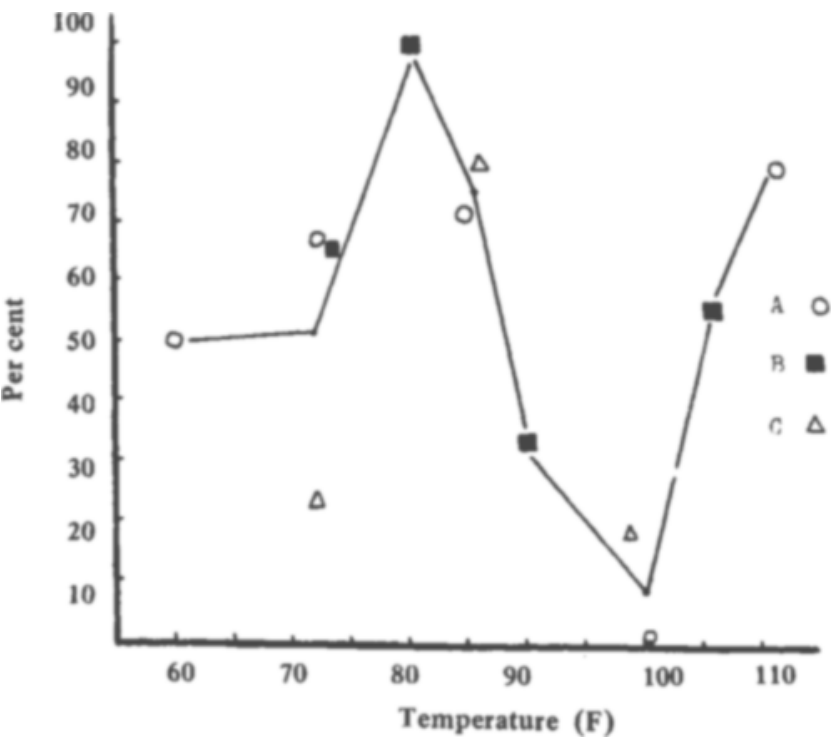

Fig. 1. The percentage of learners in each of the groups of Studies A, B, and C. are presented in Table 1.

RESULTS AND DISCUSSION

The clearest picture of the effect of water temperature on learning in this maze can be seen in Fig. 1, in which per cent learners from each of the 12 groups of the three studies are plotted. The percentages vary from " 0 " for $100 \mathrm{deg}$ to " 100 " for $80 \mathrm{deg}$. An increase in the proportion of learners as the water temperature diverges from normal body temperature (about $98 \mathrm{deg}$ ) is evident in both directions. Optimal performance is in the region of $80 \mathrm{deg}$, with $110 \mathrm{deg}$ also yielding high learning rates. At $115 \mathrm{deg}$, the Ss manifested disorganization and rapid dibilitation, a finding reported by both Wever (1932) and Hack (1933). A chi-square obtained for temperature and learning vs nonlearning (with identical or close tem-
Table 1

Summary Data for Studies A, B, and C

\begin{tabular}{|c|c|c|c|c|c|}
\hline \multicolumn{6}{|c|}{ Study A* } \\
\hline Temperature & 60 & 72 & 85 & 100 & 110 \\
\hline $\mathbf{N}(47)$ & 10 & 9 & 9 & 9 & 10 \\
\hline Md Trials & 18 & 16 & 12 & 20 & 9.5 \\
\hline Md Err/Tr & 4.0 & 5.9 & 4.0 & 5.6 & 5.5 \\
\hline Md Time/Tr & 36 & 57 & 61 & 142 & 80 \\
\hline$\%$ Learners & 50 & 67 & 70 & 00 & 80 \\
\hline $\begin{array}{l}\text { Temperature } \\
\text { N (36) } \\
\text { Md Trials } \\
\text { Md Err/Tr } \\
\text { Md Time/Tr } \\
\text { \% Learners }\end{array}$ & $\begin{array}{r}73 \\
9 \\
15 \\
3.3 \\
40 \\
67\end{array}$ & $\begin{array}{r}S \\
80 \\
9 \\
11 \\
3.1 \\
27 \\
100\end{array}$ & $\begin{array}{r}90 \\
9 \\
30 \\
2.8 \\
74 \\
33\end{array}$ & $\begin{array}{r}105 \\
9 \\
23 \\
2.7 \\
120 \\
56\end{array}$ & \\
\hline $\begin{array}{l}\text { Temperature } \\
\text { N (52) } \\
\text { Md Trials } \\
\text { Md Err/Tr } \\
\text { Md Time/Tr } \\
\% \text { Learners } \\
\end{array}$ & $\begin{array}{r}72 \\
17 \\
30 \\
3.7 \\
34 \\
23\end{array}$ & $\begin{array}{r}S \\
85 \\
19 \\
22 \\
3.3 \\
41 \\
80\end{array}$ & $\begin{array}{r}98 \\
16 \\
30 \\
3.2 \\
76 \\
19\end{array}$ & & \\
\hline
\end{tabular}

- Maxima of 20 trials and 600 seconds/Trial

** Maxima of 30 trials and 300 seconds/Trial peratures combined) was significant beyond the .001 level.

The median number of trials for each group is presented in Table 1. A separate Kruskal-Wallis analysis was computed for each study. The obtained Hs (corrected for ties) all exceeded the .05 level.

Median errors/trial for each group are presented in Table 1. Studies B and C failed to yield significant differences on this measure, a finding consistent with that of Waller et al (1960). The error difference for Study A was significant beyond the .05 level.

Time/trial is also presented in Table 1. Kruskal-Wallis analyses yielded significant differences beyond the .05 level for each study. Time scores show an overall decrease as water temperature departs from body temperature.

The findings on this maze suggest systematic relationships between learning and motivation and water temperature. Motivation, as reflected in time scores, generally increases monotonically as water temperature diverges from body temperature, i.e., time scores drop. Learning, on the other hand, based on trials and percentage of learners, bears a nonmonotonic relationship to temperature with peaks in the regions of 80 and $110 \mathrm{deg}$. Errors do not vary consistently as a function of temperature.

\section{REFERENCES}

HACK, E. R. Learning as a function of water temperature. Joumal of Experimental Psychology, 1933, 16, 442-445.

WALLER, M. B, WALLER,P.F \& BREWSTER,

L. A. A water maze for use in studies of drive and learning. Psychological Reports, 1960, 7, 99-102.

WEVER, E. G. Water temperature as an incentive to swimming activity in the rat. Joumal of Comparative Psychology, 1932, 14, 219-224. 